\title{
A Study related to the management of medical and pharmaceutical wastes in Beni Mellal-Khenifra region: Beni Mellal city as a case of study
}

\author{
Said Msaad ${ }^{1, *}$, Nouredine.Abbadi ${ }^{2}$, Mohamed.Mbarki ${ }^{3}$, Souad.Rabi ${ }^{3}$, Najat.Belkhouya ${ }^{1}$, and Ahmed.Gamouh ${ }^{1}$. \\ ${ }^{1}$ Laboratory of Applied Spectro- Chemisry and Environment. Faculty of Sciences and Technologies, University of Sultan Moulay \\ Slimane (BP) 592, Beni Mellal, Morocco.smsaadi@yahoo.fr \\ ${ }^{2}$ Laboratory of Biological Engineering. Faculty of Sciences and Technologies, University of Sultan Moulay Slimane (BP), 592, Beni \\ Mellal, Morocco. \\ ${ }^{3}$ Laboratory of Chemical Processing and Applied Materials .Multi-disciplinary Faculty, Sultan Moulay Slimane University (BP), 592, \\ Beni-Mellal, Morocco
}

\begin{abstract}
After having conducted an investigation about landfill in Beni Mellal city, Medical and Pharmaceutical Wastes (MPWs) are unloaded mixed with household and similar wastes. The objective of the present study is to analyze the management system of medical and pharmaceutical wastes at the level of Beni Mellal city in order to ameliorate the quality of collecting and handling these wastes and consequently minimizing the management costs vis a vis this service. First of all, we have created database concerning the location of health centers (HC). After, we have conducted a survey with the help of a questionnaire in different public and private health centers. Then we have carried out a research on MPWs in Dustbins existing around the health centers. We have also made an analysis of the management system of MPWs inside The Regional Hospital Center (RHC) in Beni Mellal. Afterwards, we have made a comparison between some hospital centers in Morocco when it comes to the management costs of MPWs.Based on the results obtained; we have suggested some solutions to master the management system of MPWs in addition to the scenarios for optimizing the costs linked with this service.
\end{abstract}

\section{Introduction}

The world accumulates more wastes which can be seen as any useless, unwanted or discarded substance or material, irrespective of whether or not such substance or material has any other or future use [1]. Hospitals and medical centers are not the exception. The development of medical technology has increased the production of different types of wastes, which can threaten the environment and Jeopardize human health [2]. Among these wastes, we have pharmaceutical wastes, which are seen as one of the hazardous wastes class in the hospital [3].

According to the International Health Organization, in its note in 2007, it is stipulated that there was not inexpensive options, which have no effect on the environment, for eliminating hospital wastes with safety.

In Morocco, the management of wastes is a priority for the Government to protect the environment and people's health without forgetting also that The mismanagement of health care waste poses risks to people and environment [4]. In keeping with this , Dr. Anjali along with other experts in their article claim that Improper management of health care waste can have both direct and indirect health consequences for health personnel and to the environment [5]. Since many years, the quantity of wastes produced continues to increase to the extent that it has created a challenge for the workers working in this domain; hence the quantity produced is estimated by 21000 tons per year [6].

As part of its strategy to the problematic of MPWs, the Moroccan Government, through its ministry of health, encourages private sector to invest in private processing units.

The Moroccan Government has adopted a number of laws in the domain of MPWs management which are as follows:

- Law n 28-00, November 22, 2006 related to the management of wastes and their elimination [7].

- Decree $\mathrm{N}^{\circ}$ 2-07-253, July 18, 2008 classifying wastes and listing dangerous wastes [8].

- Decree $\mathrm{N}^{\circ}$ 2-96-139, May 21, 2009 related to the management of pharmaceutical and medical wastes [9]. 
- Law $\mathrm{N}^{\circ}$ 30-05, June 2, 2011 related to the transportation of dangerous goods by roads [10].

- Law $\mathrm{N}^{\circ}$ 2-14-85, January 20, 2015 related to the management of dangerous wastes [11].

In the past, there has been a problem in law. Huge quantities of hospital wastes are eliminated without any prior processing, simply by landfill or burial method, which is viewed as one of the popular methods because all wastes after minimization or treatment need access to land or final disposal [12] as it is indicated in figure 1 . In reality, this method does not eliminate the harmfulness of wastes, but they have an effect, especially because Improperly dispose of medications potentially pose environmental risk [13], and the disposal of pharmaceutical wastes depends on Multiple factors. For example, a particular pill, depending on its characteristics, could be hazardous waste [14]. These wastes constitute a reservoir of microorganisms which can cause some diseases, like SIDA, hepatitis $\mathrm{A}$ and $\mathrm{B}$, Gastroenteritis, skin diseases, and the list is long

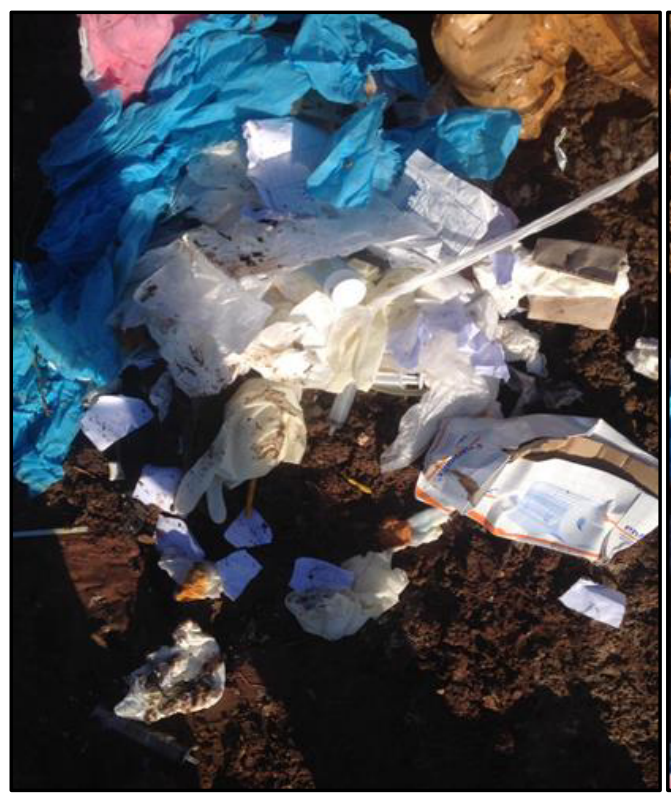

[15]. According to the Article entitled " Medical Waste Management Community Health Centers" written Mohamad Saadati along with other researchers, Some hazardous agents such as HIV, Hepatitis B and hepatitis c, are transferrable through medical wastes" [16].

Our study is the first study carried out in the domain of MPWs at the level of Beni Mellal region; it is about the problematic of managing medical and pharmaceutical wastes at the level of Beni Mellal and the objectives are to:

1) Analyze and evaluate the management system of MPWs at the level of Beni Mellal city.

2) Suggest some solutions and scenarios for optimizing the costs linked with this service.

3) Ameliorate the quality of collecting and handling wastes. or develop an ' Efficient strategy for pharmaceutical wastes disposal [17], by providing good health care risk waste management practices [18].

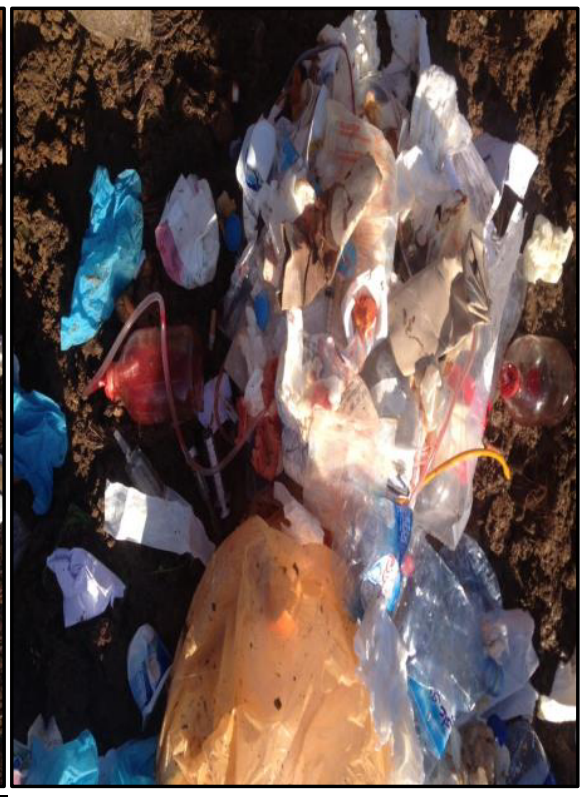

Fig.1. Identification of MPWs at The Level of Landfill in Beni Mellal (year 2017)

\section{1) Materials and methods}

We have created database concerning the location of health centers. After, we have conducted a survey with the help of a questionnaire (see annex1), and we have looked for MPWs in the dustbins existing around The health centers. We have analyzed and evaluated the management system of MPWs inside RHC in Beni Mellal. Then we have made a comparison between the costs of eliminating wastes in Beni mellal with others in other cities in Morocco (sorting out, intermediate storage, final disposal and processing them according to their nature).
To carry this work, we have used the following materials:

- Excel;

- Andlocalisation: Localisation;

- ArcGis: Geolocation Information system (GIS);

- Sphinx: Elaboration of the questionnaire.

\section{Presenting the area of study}

Beni Mellal city is the biggest city and the capital city of Beni Mellal- khenifra region. It is located in the Centre of Morocco, $240 \mathrm{~km}$ away from Rabat, $200 \mathrm{Km}$ away from Casablanca, and $190 \mathrm{~km}$ away from Marrakesh city (figure 2). 


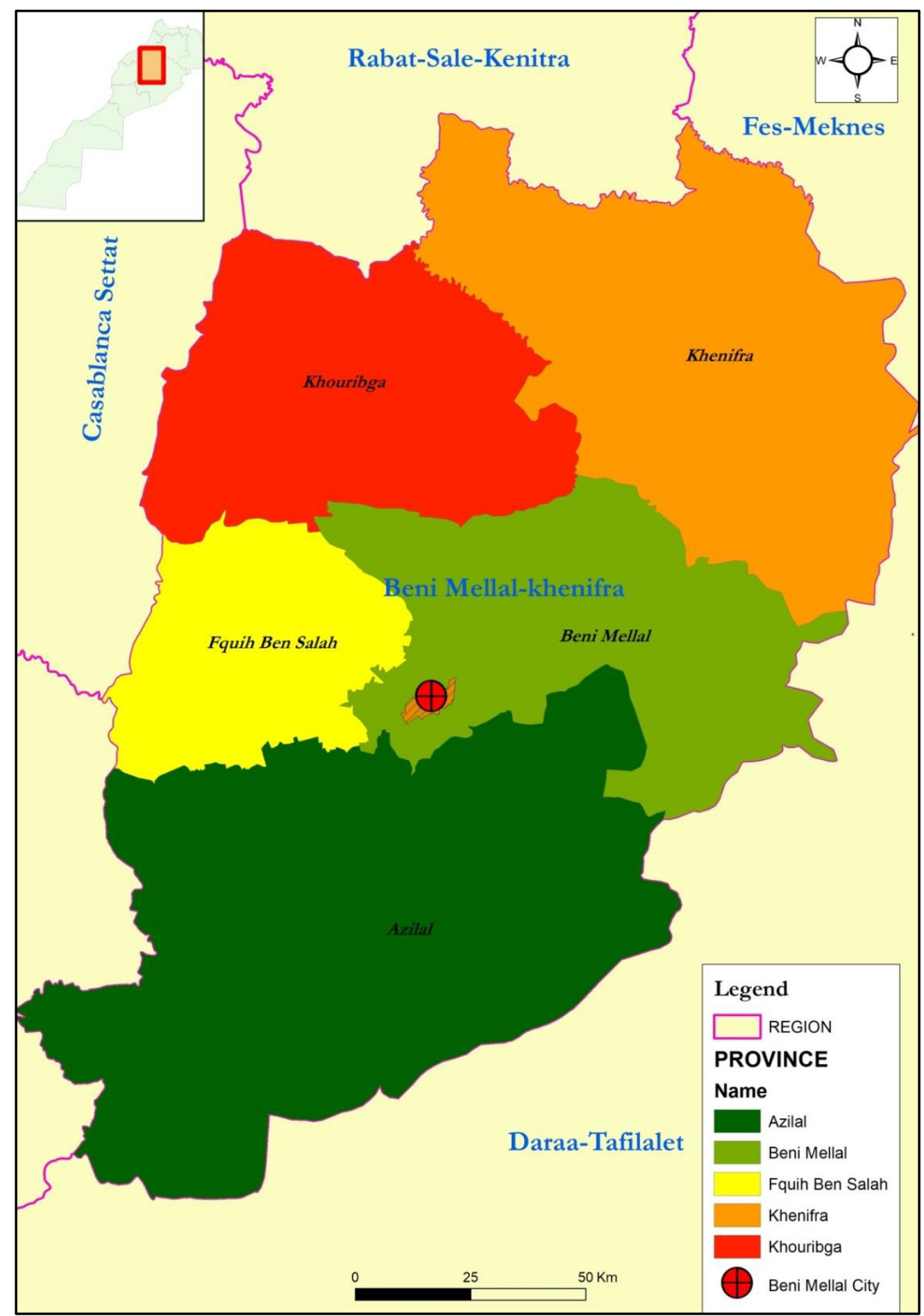

Fig.2. The location of Beni Mellal in Beni Mellal- Khenifra Region [19].

\section{2) Results and discussions}

\subsection{Health Centers in Beni Mellal:}

We have identified 30 health centers existing in different areas in Beni Mellal city, where its location is indicated in the plan of annex 2 .

The number of each type of health center is illustrated in the table 1 below:
Tab.1. Number of each type of health center

\begin{tabular}{|c|c|c|}
\hline \multicolumn{3}{|c|}{ Health Centers in Beni Mellal City } \\
\hline $\begin{array}{l}-1 \quad \text { (one) } \\
\text { Regional } \\
\text { Hospital } \\
\text { Center } \\
\text { Primary } \\
\text { Health } \\
\text { Center }\end{array}$ & \begin{tabular}{|ll}
- & 2 \\
& Hemodialysis \\
& Centers \\
- & 5 \\
& Medical (five) \\
& Analysis \\
& Laboratories
\end{tabular} & 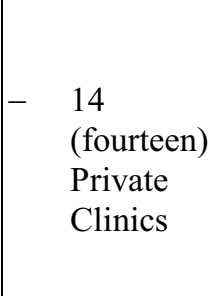 \\
\hline
\end{tabular}


Conducting a survey with the help of a questionnaire inside the health centers in Beni Mellal.

We have conducted an investigation inside a number of health centers, and the results are the following:

- Given the sensitivity of the sector and for the confidential reasons, just $33 \%$ of health centers have answered the questionnaire.

- $60 \%$ of the participants know about the legal framework of MPWs.

- $100 \%$ of the participants have confirmed that MPWs have hazardous effects on public health and environment.

- $50 \%$ of the participants investigated have benefited from a training in relation to the management of MPWs

- $100 \%$ the centers inquired have made some conventions with private operators about the management of MPWs.

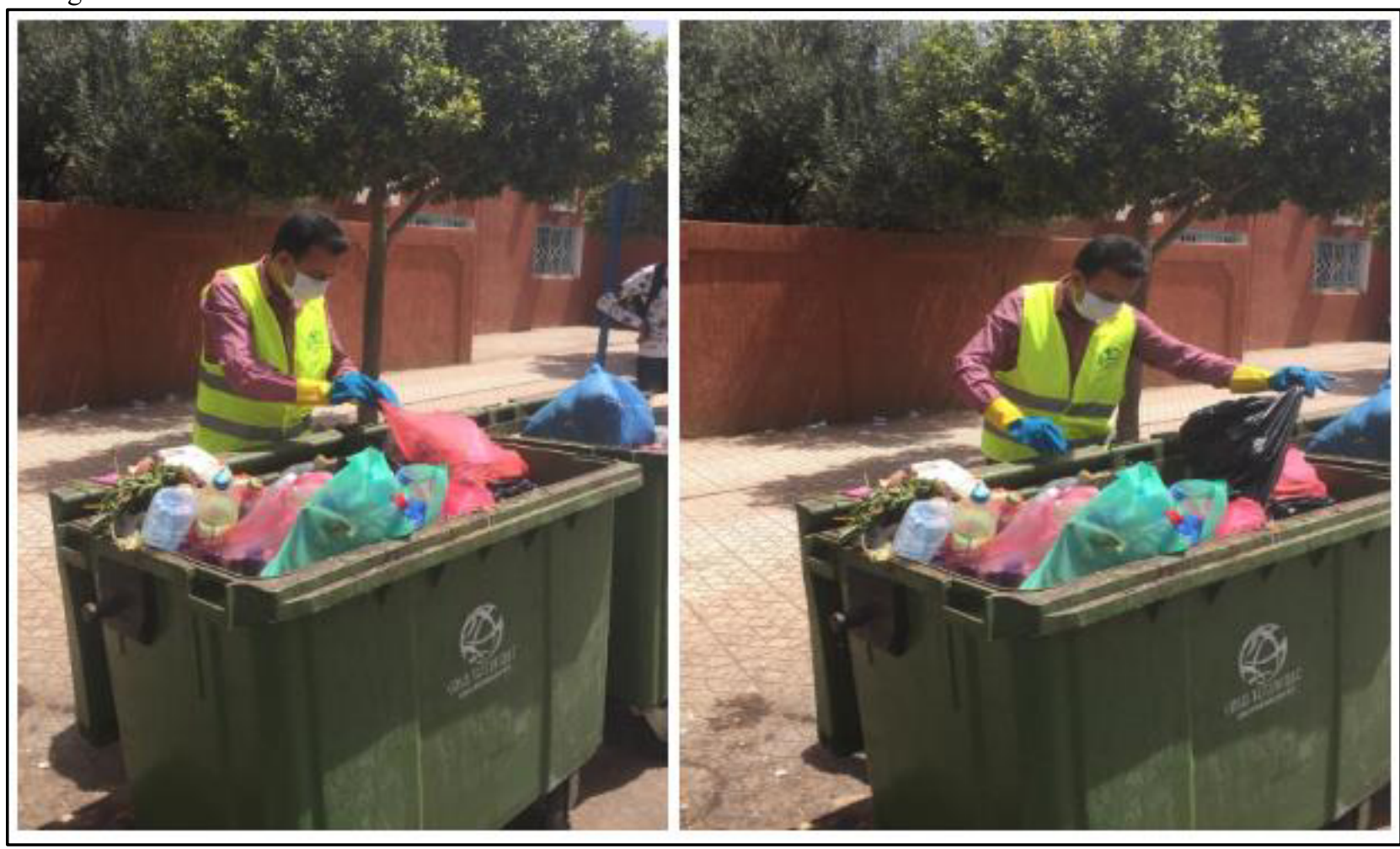

Fig.3. Searching for Medical Wastes in Garbage bins existing around The Health Centers.

\subsection{Analyze and Evaluate the Management System of MPWs inside RHC in Beni Mellal}

The objective of this stage in our study is to make an audit inside RHC in Beni Mellal so as to see the degree of respecting the procedure of managing MPWs inside every service.

The amount of hospital wastes, Household and similar wastes produced by RHC in Beni Mellal is indicated in the table below.
- $100 \%$ of health centers inquired have appointed a person responsible for monitoring the management of MPWs.

- Sorting out and MPWs conditioning constitute 100\% in the private health centers and less in the public ones.

- $100 \%$ of health centers investigated have a place for storing MPWs.

\subsection{Carrying a survey about MPWs in the garbage bins around the health centers.}

This investigation is demonstrated in (Figure 3). We have looked for MPWs in every dustbin existing near the health centers.

The result of this operation is negative. There are no MPWs in those dustbins. 
Tab.2. The Amount of Hospital Wastes Produced by RHC in Beni Mellal in 2018 [20].

\begin{tabular}{|c|c|c|}
\hline Month & MPWs & $\begin{array}{l}\text { Household and } \\
\text { similar wastes }\end{array}$ \\
\hline January & 6122 & 11905 \\
\hline February & 4734 & 12160 \\
\hline March & 6450 & 13024 \\
\hline April & 5397 & 14071 \\
\hline May & 6180 & 14215 \\
\hline June & 5834 & 16315 \\
\hline July & 6171 & 16978 \\
\hline August & 6181 & 16606 \\
\hline September & 6761 & 15865 \\
\hline October & 5990 & 13981 \\
\hline November & 5404 & 13195 \\
\hline December & 6140 & 11650 \\
\hline Total Quantity (Kg) & 71364 & 169965 \\
\hline $\begin{array}{l}\text { Average Quantity } \\
\text { (Kg)/Month }\end{array}$ & 5947 & 14164 \\
\hline $\begin{array}{ll}\text { Total } & \text { Average } \\
\text { Quantity (Kg) / } \\
\text { Month }\end{array}$ & 20111 & \\
\hline
\end{tabular}

After analyzing the quantity of MPWs produced by RHC in Beni Mellal, it is observable that the maternity section produces more MPWs (see the quantity produced in the graph below).

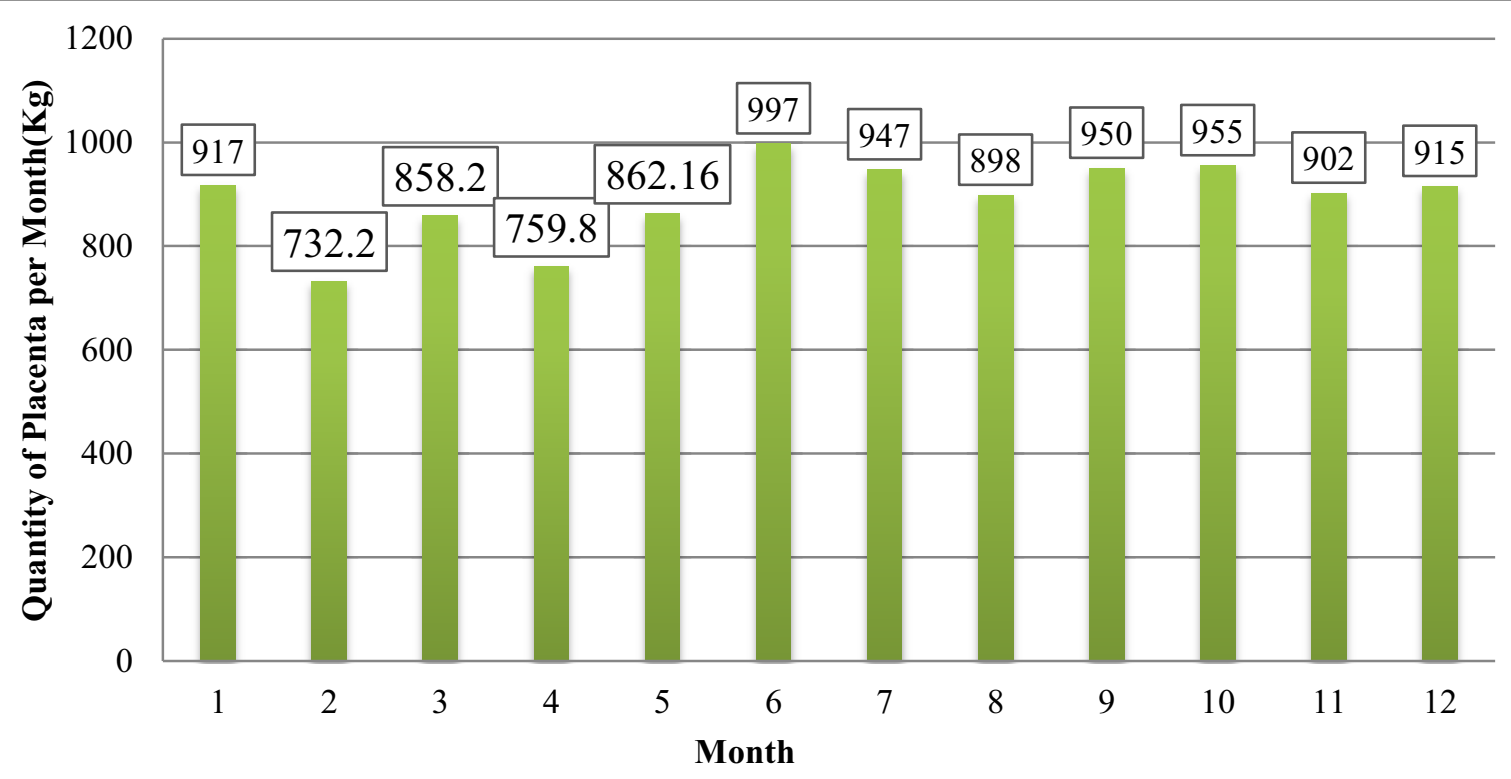

Fig.4. the Quantity of Placenta Produced by the Maternity Section inside RHC in Beni Mellal in 2018

The average quantity of Placenta produced by the maternity section in RHC in Beni Mellal in 2018 is $891.11 \mathrm{~kg} / \mathrm{month}$. It represents $15 \%$ of MPWs.

2.4 A Comparison between the Costs of Eliminating MPWs in Beni Mellal with Other Cities in Morocco ( Sorting out, collecting, intermediate storage, final evacuation, and processing depending on their nature)
A comparative study about the costs of managing MPWs in different hospital centers in Morocco has been conducted, and the costs of this management are presented in the table 3 and figure 5 . 
Tab.3. A Comparative Table about the Costs of Handling Medical Wastes in Different Hospital Centers in Morocco $[21]$.

\begin{tabular}{|l|c|c|c|}
\hline \multicolumn{1}{|c|}{ City } & Quantity (Kg) & Amount (Dhs) & Costs (Dhs/Kg) \\
\hline Prefectural hospital center- Agadir ( PHC) & 120000 & 628560 & 5.2 \\
\hline RHC Béni Mellal & $\mathbf{1 2 0 ~ 0 0 0}$ & $\mathbf{8 6 4 0 0 0}$ & $\mathbf{7 . 2}$ \\
\hline PHC Essaouira & 49500 & 259000 & 5.2 \\
\hline Hospital-university Mohammed VI center -Marrakech & 288000 & 1900800 & 6.6 \\
\hline PHC Al-Hoceima & 56452 & 623073.60 & 11.03 \\
\hline PHC Tinghir & 13000 & 255060 & 19.62 \\
\hline
\end{tabular}

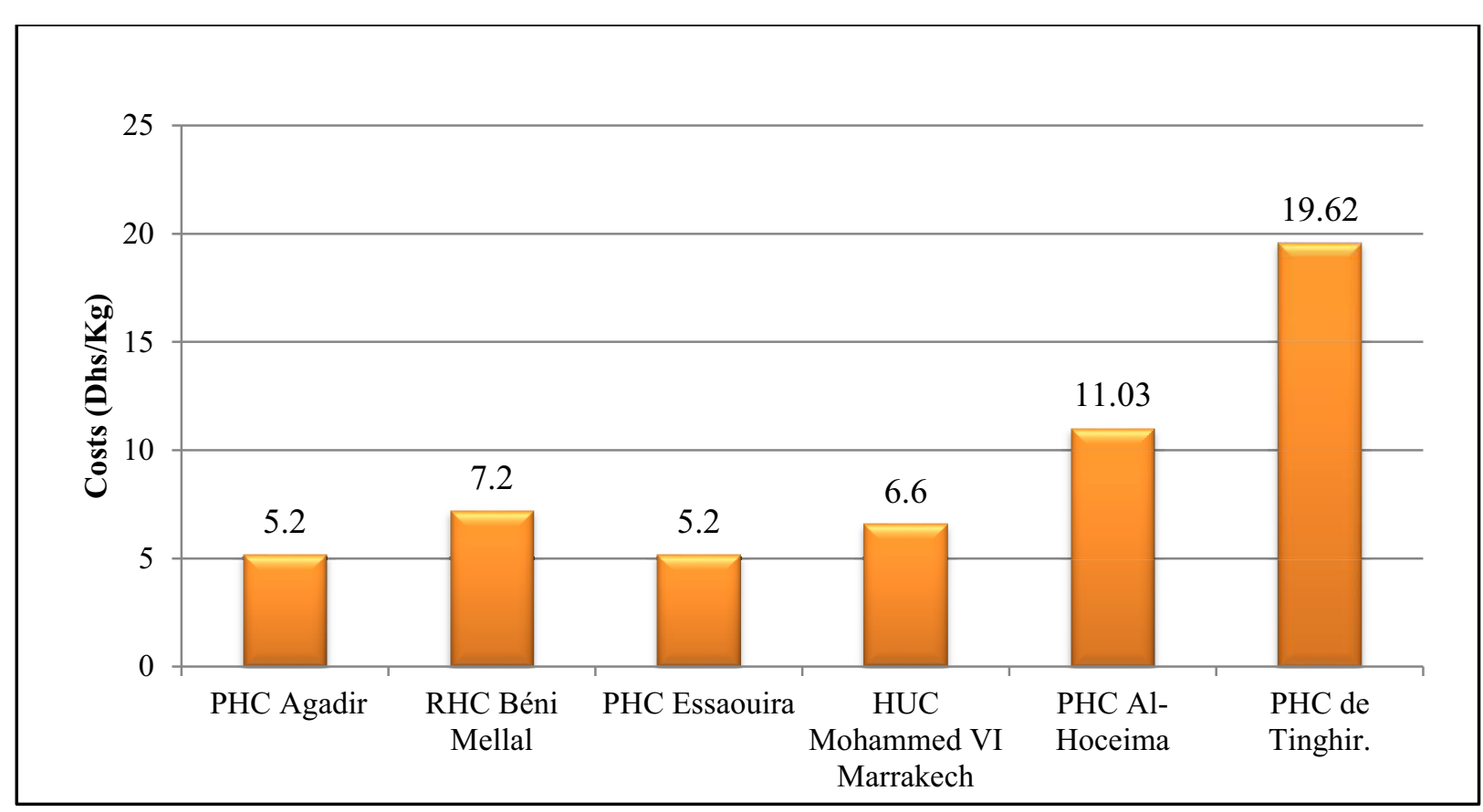

Fig. 5. Comparing the Costs of Processing Medical Wastes in Different Hospital Centers.

The analysis of different previous results has led us to formulate the following remarks:

- The necessity of enhancing training and sensitization side of the staff working in those health centers for better understanding of the process of eliminating MPWs;

- Private health centers master well the management of MPWs better than the public ones;

- Periodic maintenance of materials of managing MPWs inside RHC is a factor determining the process of management;

- The cost of eliminating MPWs inside Beni Mellal city is slightly high, and it depends basically on how far are they from the processing sites and the quantity to be processed.
Our work has brought up results which are the first in the domain of managing MPWs at the level of Beni Mellal region. These results have led us to diagnose the mode of managing MPWs at the level of the region and detect the defects that exist.

Improving the management system of MPWs at the level of each health center is necessary. This improvement focuses on sensitization and staff training, offering equipment for handling MPWs. There must be necessarily a control over these health centers by paying unexpected visits and suggesting some improvements every time if necessary.

Given its potentials and geographical vocation, Beni Mellal city has an important industrial zone, and installing a processing unit for MPWs with a great amount of capacity would allow to:

- $\quad$ Reduce the costs of transporting MPWs;

- Minimize the duration of MPWs storage; 
- Encourage different private health centers to adhere to this unit with competitive prices;

- Possibility of managing MPWs at the regional level;

- Offering more job opportunities at the level of the region.

\section{References}

1. Renju Rajan, Delvin T. Robin, Vandanarani M. Biomedical waste management in Ayurveda hospitals-current practices and future prospectives. Journal of Ayurveda and Integrative Medicine,10 (2019), p 214.

2. Mohammad Hadi Dehghani, Hamid Dashti Ahramia, Ramin Nabizadeha, Zoha Heidarinejadd,Ahmad Zareif. Medical waste generation and management in medical clinics in South of Iran. MethodsX, 6 (2019), p 1.

3. Samuel Sasu,Klaus Kümmerer, Martin Kranert. Assessment of pharmaceutical waste management at selected hospitals and homes in Ghana. Waste Management \& Research, 30(6) (2012) P 626.

4. Lars M. Johannessen, Marleen Dijkman, Carl Bartone, David Hanrahan, M. Gabriela Boyer, Candace Chandra. Health Care Waste Management Guidance Note. (2000)May, p 1.

5. Dr. Anjali Acharya, Dr. Vasudha Ashutosh Gokhale, Deepa Joshi. Impact of Biomedical Waste on City Environment: Case Study of Pune. India. IOSR Journal of Applied Chemistry, Volume 6, Issue 6 (Jan. 2014), P 22.

6. Faiza Rhoul. Management of medical wastes: "We must follow hospitals and clinics". Yabiladi [online]. (2018). Available on: https://www.yabiladi.com/articles/details/69034/gesti on-dechets-medicaux-faut-poursuivre.html

7. The general Secretary of the Government, Morocco. Law $\mathbf{n}^{\circ}$ 28-00 of November 22, 2006 relative to the Management of wastes and their elimination. Official bulletin ulletin $\mathrm{N}^{\circ} 5480$ of 15 Dhul Qa'dah 1427 (December 7, 2006)

8. General Secretariat of the Government, Morocco. Decree $n^{\circ} 2-07-253$ of July 18, 2008 classifying waste and listing hazardous wastes 2008 classifying waste and listing hazardous wastes. Official bulletin $\mathrm{N}^{\circ} 5654$ of July 7, (2008).

9. General Secretariat of the Government, Morocco. Decree $n^{\circ}$ 2-09-139 of Mai 21,2009 relative to the management of medical and pharmaceutical wastes. Official bulletin $\mathrm{N}^{\circ} 5744$ of 24 jumada II 1430 (June 18, 2009)

10. General Secretariat of the Government, Morocco. Law $n^{\circ}$ 30-05 of Jun 2,2011 relative to the the transport of dangerous goods by roads. Official bulletin $\mathrm{N}^{\circ} 5956$ bis of 27 rajab 1432 (Jun 30,2011), p.1765-1772
11. General Secretariat of the Government, Morocco. Decree $\boldsymbol{n}^{\circ}$ 2-14-85 of January 20, 2015 on the management of hazardous waste Official bulletin $\mathrm{N}^{\circ} 6336$ of 29 rabi II 1436 (February 19, 2015)

12. Mohsen Ansaria, Mohammad Hassan Ehrampousha, Mahdi Farzadkia, Ehsan Ahmadie. Dynamic assessment of economic and environmental performance index and generation, composition, environmental and human health risks of hospital solid waste in developing countries; A state of the art of review. Environment International, 132 (2019), P 20 .

13. Md. Abul Kalam Azad, Md. Rezaul Haque Ansary Md. Akhtaruzzaman Akhter, S. M.Mostofa Al-Mamun, Mohi Uddin and M.M.Rahman. Disposal Practice for Unused Medications among the Students of the International Islamic University Malaysia. Journal of Applied Pharmaceutical Science 02 (07), (2012), p 2.

14. Bryan W. Shaw, Buddy Garcia, Carlos Rubinstein, Mark R. Vickery, Study of the Methods for Disposing of Unused Pharmaceuticals.texas commission on environment quality (2010 December), p 35

15. T. AJZOUL. Alternative option for handling hospital waste in Morocco: The choice between burial, incineration and autoclaving. In: First National Conference on medical Wastes: Management and its impact on Health and Environment, March 30-31, (2007), Faculty of Sciences, Meknes, Morocco, p. 1

16. Jafar Sadegh TABRIZI ,Ramin REZAPOUR, Mohammad SAADATI , Samira SEIFI , Behnam AMINI , Farahnaz VARMAZYAR. Medical Waste Management in Community Health Centers. Iran J Public Health, Vol. 47, No.2, (2018 Febrary), p 287.

17. Simona Bungau, Delia Mirela Tit, Katalin Fodor, Gabriela Cioca, Maricel Agop,Ciprian Iovan , Delia Carmen Nistor Cseppento , Adrian Bumbu, Cristiana Bustea. Aspects Regarding the Pharmaceutical Waste Management in Romania Sustainability, 10 (2018), p 11.

18. Mr WD Khanyile. Health Kwazulu-Natal. Policy for Kwazulu-natal: Health care risk waste management. Reference 16/1/P, (2008 January), p 13.

19. The General Directorate of Local Government, Morocco. Monograph about Beni Mellal - Khénifra region, p.3.

20. Beni Mellal Regional Hospital Center. Waste tonnage documents 
21. Public Procurement Platform. Medical and pharmaceutical waste management [online].
Available on the

https://www.marchespublics.gov.ma link: 